\title{
A Survey on Human Computer Interaction Technology for ATM
}

\author{
Mengxing Zhang, Feng Wang*, Hui Deng, Jibin Yin \\ Computer Technology Application Key Lab, Kunming University of Science and Technology \\ *Corresponding author's Email: zhangmengxing@cnlab.net
}

\begin{abstract}
Human computer interaction technology has been applied too much in Automated Teller Machine's design, such as interface design. In this paper, we have done a survey on human computer technology for ATM and presented an investigation of the ATM's design on the precious literatures. The user experience test and evaluation of the prototype are reviewed and discussed in details, and we find the defects and the improvement of the ATM's design. In the end, we propose some suggestions and discussion in future works.
\end{abstract}

Keywords: Human computer interaction; ATM; Financial terminal; Interface design

\section{Introduction}

In our life, there are so many financial terminals and the most in common is Auto Teller machine (ATM). Now in the fast-pace society and the information age, the rhythm of our life is highly nervous, I think no one want to spend a lot of time in lining at the bank just to wait for the crowded business. Constructing a 24 hour system without specific time limit is very necessary. We can handle business when we have time, we need not go to row the boundless line any longer, and this is undoubtedly the best choice. In order to solve the problem, the financial terminal appeared-the Auto Teller machine (ATM). ATM's birth has provided a lot of convenience for human life.

ATM also referred to a cash machine, a cash dispenser among other names, which is an electronic computerized telecommunications device that allows financial institution (e.g. bank) customers to directly use it in a secure communication method to access their bank accounts. ATM is a self-service banking terminal that accepts deposit and withdrawal cash. Most ATMs also let users carry out other banking transactions (e.g. check balance). ATM is activated by inserting a bank card (cash or credit card) into the card reader slot. On the card magnetic stripe, there are the customer's account number and PIN (Personal Identification Number). For example, when a customer is trying to withdraw cash, ATM first connects the bank computers to verify the balance, then dispenses the cash and transmits a completed transaction notice at last.

ATMs have been almost classified as a new technology in almost every country. The ATM can offer significant benefits to both banks and customers.

Banks usually try to use technology for internal use and communication from the beginning and later as a tool to serve their customers. For this, Jun and Cai stated the research of that, "Customers perceptions of service quality and their satisfaction are profoundly influenced by their service encounters" [25]. Beginning in the early 1970 s and following the introduction of credit cards, the next important technology was the development of ATMs which started to perform most of the teller duties in the bank.

ATMs network contributed significantly in performing most of the customers' financial services in a reliable way [26]. According to Mcandrews [27], ATMs can offer significant advantages to both banks and customers. The machines can enable depositors to with- 
draw and deposit cash at more convenient times and places than during banking hours at branches. At the same time, by automating services that were previously completed manually, ATMs can reduce the costs of servicing for some customer demands. These potential advantages are multiplied when banks share their ATMs with others, allowing depositors of other banks to access their accounts through a bank's ATM.

According to Maenpaa, Kale, Kuusela and Mesiran$\mathrm{ta}[28]$, security can stand for the reliability of an innovation and an overall belief on the part of the user that banking transactions can be completed confidentially and safely. Study by Rogers, Gilbert and Cabrera's [29] asked the eight non-users if they had any concerns about using ATMs. The result of the study indicated that most of them have mentioned safety as the main concern. This result is almost similar to that of Mirza, Beheshti, Wallstrom and Mirza's study in respect to internet banking (IB) [30]. However, Rogers et al. [27] interviewees also focused on many issues related to safety and security. These include, for example, their inability to use ATMs in a remote location especially in the evening. In this context, the majority of ATMs today are located at sites other than banks such as malls and grocery stores [31]. Study of Maenpaa et al. focused on many aspects for security of internet banking users, most of which are also related to ATMs. These include privacy of their bank transactions and safety of their bank transactions. Study by Adepoju and Alhassan revealed that the security level is poor in Nigerian banks as some banks do not offer any tools where customers can easily report cases of ATM fraud. In respect to ease of use [32], it has been defined as the degree to which an innovation can be understood and used in a simple and easy way.

However, previous literature introduced a series of challenges and difficulties that prevent the proper use of ATMs. Rogers et al. study showed that some intermediate users have some difficulties in using ATMs such as inserting the card in the wrong way, lacking experience and inconvenience. On the other hand, the frequent users indicated that ATMs don't provide enough feedback and can't respond quickly enough. Another study by Rogers, Cabrera, Walker, Gilbert and Fisk [33] asked the respondents to identify the actual or perceived difficulties with ATMs. The result$\mathrm{s}$ indicated that young, middle-aged and young-old adults rated having to wait in line to use the machine highest in difficulty, while old adults rated being able to see the screen well highest. They also asked the respondents to rate their actual or perceived difficulty with performing different transactions on ATMs. The results indicated that all age groups rated making payments as the most difficult. However, the overall pattern of difficulty was almost similar across age groups. For example adults of all ages see making withdrawals and balance checking to be easy, whereas making deposits, cash advances, transfers and payments to be progressively harder. Taking another banking technological innovation, Jun and Cai focused on investigating the main dimensions of internet banking service quality according to internet banking customers and tried to determine critical, satisfying and dissatisfying factors among the identified dimensions. Using a content analysis, they identified six dimensions of online systems quality. These include content, accuracy, ease of use, timeliness, aesthetics and security. The study findings indicated that ease of use of internet in this case has many aspects. These include compatibility, user friendly, easy login, speed of responses, accessibility of the web site, functions that customers need and easy navigation. Most of these aspects are also applicable to the ATMs usage. The current study selected three important factors, namely; low cost services, privacy and security and ease of use to assess their influence on achieving the users' financial need satisfaction.

ATM, which has been widely applied, has played a significant role in people's lives, but meanwhile, defrauding means began to emerge endlessly by taking advantage of ATM, such as huge security holes, peeping at passwords, exchanging fake cards, installing miniature camera head and fake keyboard. ATM has security keys programmed. Between the ATM, the bank and the network processor, the code changing can guarantee the credit of access and the safety of ATM card numbers by scrambler.

Then we will analyze the progress of ATM's design through the investigation and study of the existed AT$\mathrm{M}$ to find the efficiency and improvement of the ATM.

\section{HCI Technology Application in ATM}

Human computer interface (HCI) is a term used to describe the interaction between users and computer$\mathrm{s}$; in other words, the method by which a user tells the computer what to do, and the responses which the computer makes. Even more, $\mathrm{HCI}$ is about designing computer systems to support people's use, so that they can carry out their activities productively and safely. All of this can be summarized as "to develop or improve the safety, utility, effectiveness, efficiency and usability of systems that include computers" [1]. If 
ATM were more usable then they would become more effective and efficient machines, then users would find it easier to use them. It would help the users to spend less time to use the machines and to carry out more efficient transactions.

In order to produce a good ATM system with good usability HCI specialists strive to understand the factors which determine how people operate and make good use of the ATM effectively and develop tools and techniques to help designers ensure that ATM are suitable to achieve efficient, effective and safe interaction both in terms of individual and group interactions [2].

\section{The General ATM}

\subsection{The ATM user interface}

The in the design of the ATM, the most important is the man-machine interface, namely the user interface. The ATM's user interface remains consistent for each ATM, which includes the main screen, the selection keys, the keypad and several slots. This is illustrated in Figure 1.

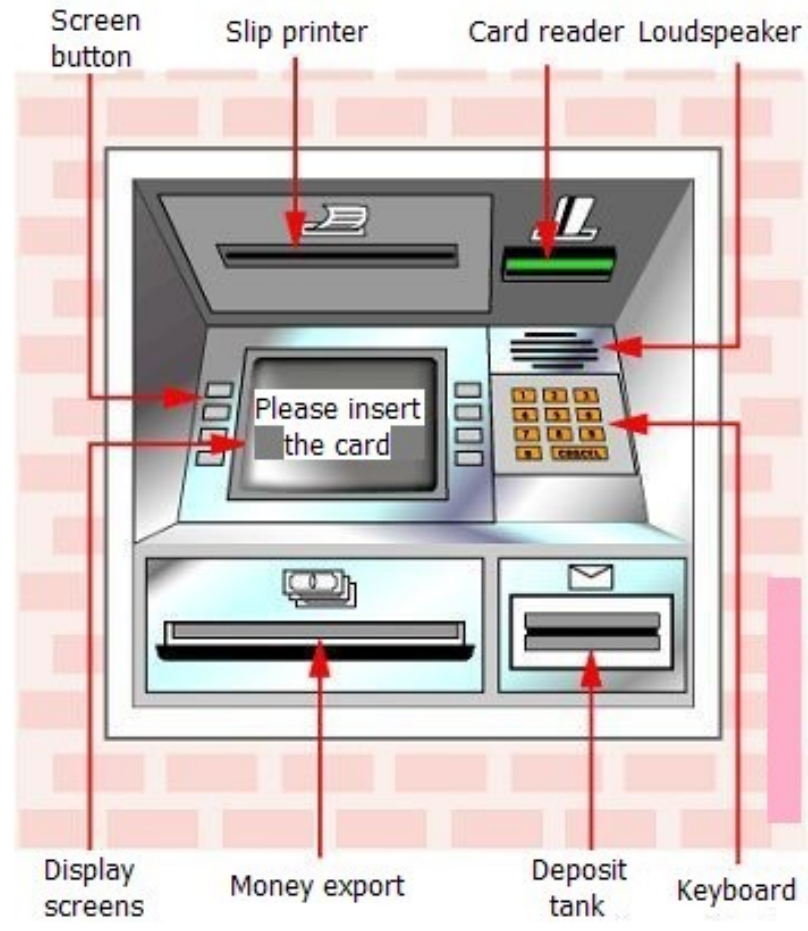

Figure 1 The general ATM's operation panel

Figure 1 is a real ATM machine. However, we often use the simulator ATM interface in the research. Figure 2 is a picture of simulate ATM.

\subsection{The ATM interface fuction}

As shown in the figure 2, either side of the ATM screen has four selection keys, which enables users to

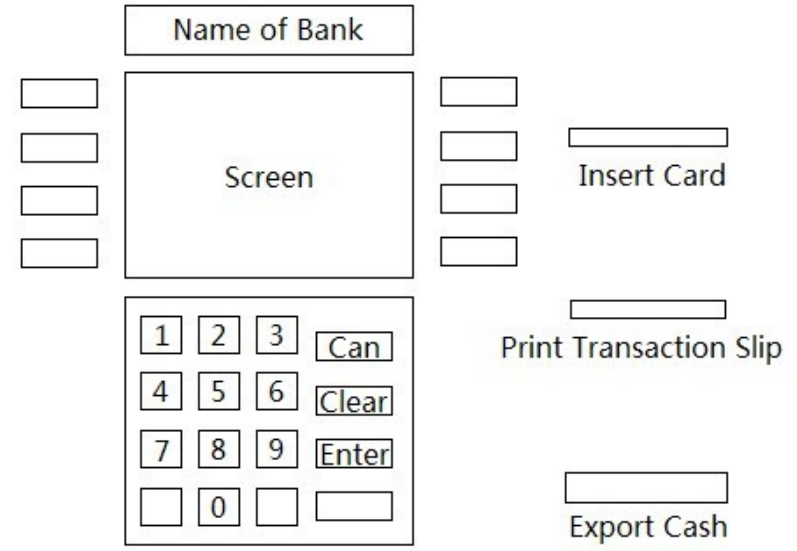

Figure 2 ATM simulator interface design

select the factions from the menu. There are also some other keys: the "Insert Card" will be used to insert the ATM card into the machine; the "Print Transaction Slip" is used to print the receipt of this operation; in addition, users can use the "Export Cash" export to get the cash. Beyond that, there is a keypad in the interface. The keypad contains the digits 0-9 and the keys "Cancel", "Clear" and "Enter" are standard for all the various types of ATMs investigated in this research.

In the General ATM, the click event is triggered when the "Enter" key is clicked in the ATM. To selec$\mathrm{t}$ an option from the menu, the user simply clicks on the select key adjacent to the menu option displayed on screen. It is the same when using an ATM in reallife; the user only presses the selection key with their finger. The user can only move onto another menu screen after an input when choosing an option.

\subsection{ATM's general using steps}

- Insert card

- Enter PIN (General 6 digits)

- Choose transaction option (Withdraw cash)

- Select/Enter amount of cash to be withdrawn

- Take cash

- Receipt? (Yes/No)

- Print receipt (Choose No will leap over this step)

- Ejected Card? (Yes/No)

- Card ejected from ATM (Choose Yes)

- Back to Main Menu (Choose No)

- Enter PIN 
- Choose transaction option (Balance Enquiry)

- Return card

Figure 3 is the ATM menu tree structure. In the tree structure, each box represents a particular menu screen.

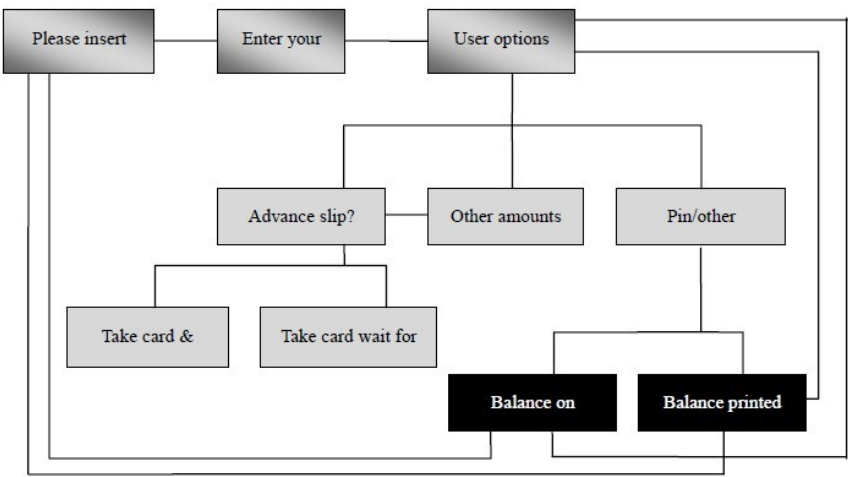

Figure 3 ATM menu tree structure

\section{The Research History of ATM}

A number of studies have already been put forward about ATM's design. Most of these studies have focused on ATM's use in relation to the age of user$\mathrm{s}$ and user disabilities (such as blindness). Adams and Thieben (1991), Mead et al. (1996), Rogers et al. (1997) and Rogers and Fisk (1997) concentrate on ATM use in relation to the age group of the users. Mankze et al. (1998) focus on ATM usability by the blind while Hone et al. (1998) focus on modes of control for ATM's including voice control. Rogers et al. (1994) say that they have been informed by banking staff that training is not necessary for ATM's because they are inherently user friendly [12] [13] [14] [15] [16] [17].

Despite the large amount of work related to the usability of web sites and web applications, there is a lack of empirical studies addressing usability of ATMs. In 2005 Wells Fargo (one of the most important Bank in the U.S.A.) re-designed user interfaces of their ATMs in order to improve customer satisfaction and user experience. This result has been achieved by both improving the aesthetic appeal of the interface and using touch screens as input/output devices; a set of profile-based functions are implemented in the system. This latter is able to recognize the most frequent operation made by the user offering him/her shortcuts.

The psychologist Aronld Wolfers thinks[22]: "security, in the objective meaning, indicates no risk to the obtained values; in the subjective meaning, indicates the fears caused by being attacked by the inexistent values." The statement can be summarized in this way: what is called security means no risk in objective aspect and no fear in subjective aspect. The problem of ATM secure interaction refers to various security problems that users meet when using ATM, mainly involving two aspects: on one hand, the intentional artificial risks from the outside when users are using, which is also the most common in current AT$\mathrm{M}$ criminal cases, such as fake retaining cards, fake hints, fake notices, fake SMS, fake keyboard to steel numbers, substituting cards, peeping at numbers, steeling numbers, making fake cards and even passing off as bank officers, and so on. On the other hand, the psychological security in the process of users' using mainly refers to users' own psychological fears and controllable losses caused by distrust and misoperation. For example, the common situations are as follows: the card may be retained if wrong passwords have been tried for three times, or the deposit does not show in the account book; and, the applicable aspects like inserting the cards in the wrong side also make users displeased.

In order to solve these problems, the scholars have also done a lot of experiments and researches, made a series of studies to improve ATM's design.

Marco Camilli and his team have done a lot of studies bout the user-centered design approach for interactive kiosks. In the present study of Marco Camilli, they investigated the relation among user experience, usability and the introduction of customized functions (based on users' profiles) in a bank's ATM system interface [6]. Then a redesign process has been carried out based on results obtained from the usability tests and on the introduction of profile-based functions to solve usability problems and to improve the overall user experience. A prototype has been developed and tested to compare the user experience and the usability between the old and the new interface and to check the effectiveness of design strategy.

The study by Kevin Curran and David King examines a variety of UK Bank ATM navigation menus and proposes a best of breed ATM menu. This research paper focuses on the user interface design problems [4]. ATM navigation menus could be improved considerably to make ATM's more usable [5].

On Chen Jinping's study [24], design of ATM secure interaction can be analyzed. Besides the classical interaction principles of conforming to coherence, minimum memory, feedback and feed forward, there 
are also some rules to conform to aiming at various questions and characteristics of ATM secure interaction. Chen Jinping has made practical proof of design in the process of theoretic research and proposed the design concept of simplified ATM based on the above design principle of ATM secure interaction.

Getting through with these important researches, we can summarize a lot of experience from which the design of ATM can be improved.

\section{The Improvement of ATM}

ATM is among the most commonly used public kiosks. During these years, bank institutions have been challenging a service innovation opening new channels for providing their services. They have also enhanced their terminals by adding a wide range of services. However, despite their importance and an increasing number of functions, ATM interface often show usability defects and the user experience could be frustrated [2].

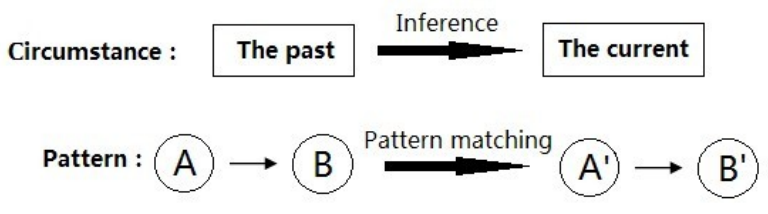

Figure 4 Mechanism of users' thinking model

To the user the interface is the product, a frustrating experience and usability problem will have consequences on ability of users to achieve their goals. We will list several important cases to introduce the improvement of ATM's design.

\subsection{The approach of user-centered design for AT- M}

In Marco Camilli and his team's experiment, they have adopted the Heuristic Evaluation; first of all they evaluated the original model, after that, they improved the design according to the evaluation results.

Heuristic Evaluation is pointed to use a content analysis. Jun and Cai (2001) identified six dimensions of online system quality, which include content, accuracy, ease of use, timeliness, aesthetics and security.

These studies indicated that using internet in this case has many aspects, including compatibility, user friendly, easy login, speed of responses, accessibility of the web site, functions that customers need and easy navigation. Most of these aspects are also applicable to the ATMs usage. A camera recorded the interaction of the user with the ATM interface and the keypad.

In the current study, the usability and the user experience of ATM of Banca Carige was assessed by using both a heuristic evaluation and test with users. The heuristic analysis of the original ATM system showed a basic and plain design strongly focused on@few main functions. Moreover, results pointed out several usability issues affecting labeling, navigation and controls. The ATM was not always self explicative and when users were required to digit many inputs, the system was not able to predict errors (e.g., providing feedbacks) and did not offer quick way to recover: when the user made a mistake which was forced to quit the operation and insert the card again. These criticisms may be caused by a function-oriented design that neglected users' needs and expectations. Figure 3 is the test with users. A camera recorded the interaction of the user with the ATM interface and the keypad.

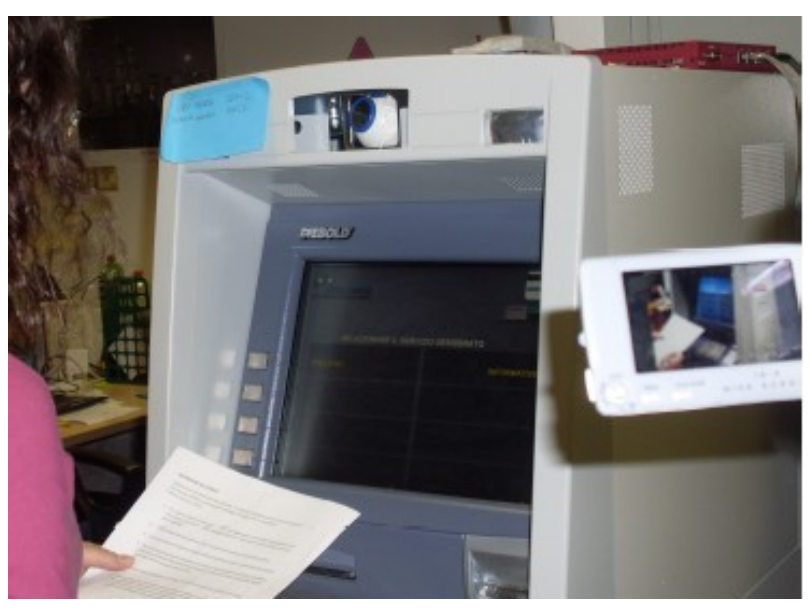

Figure 5 A picture from a user test session

After the above analysis, they redesign their system. The evaluation of the original version of the ATM showed some usability criticism and a design strongly oriented to the functional system's features. A partial redesign of the system was carried out with the following aims:

- Solving the usability problems.

- Centering the system design on specific users' needs.

With that in mind, the system redesign implemented two new user profile based functions. This type of redesign was based on a hypothetical integration between the ATM and the Customers Relation Management system (CRM). Currently, CRM systems are 
able to store both customer-profile information and the frequency of transactions performed at the ATMs. The current redesign proposes a sort of adaptive interface with functionalities based on user-profile information. In real world systems, "profile-based functions" might be activated by data provided by the CR$\mathrm{M}$ system. More generally, this redesign was based on the hypothesis that the integration between CRM and ATM will be a new and innovative channel of communication between bank institutions and their customers.

Different from the original version, the entire new interface was designed for a touch screen system. As that area was meant to speed up the interaction with the ATM, it was added in the left part of the screen, to be the first thing read by the user. Therefore, users can make their decision easily. In other words, the users' operation can be more efficient.

\subsection{The approach of optimal menu design for AT- M}

The modern ATM is more than a simple cash dispenser. In Kevin Curran and David King's research, they have introduced the standard UK ATM which offers relatively basic services including cash withdrawals, balance checks and the ability to top-up payas-you-go mobile phones. ATM in different countries (such as USA and Japan) tends to offer advanced services which include cash deposits, cheque deposits, paying bills, purchasing tickets and purchasing stamps. So the design of an ATM should not only include its inherent usability but also its perceived usability.

A good interface design can help to ensure users carry out task easier when the using the system, which has the following characteristics [4]:

- Safely-it is important for safety-critical software systems; such as software for a jumbo jet for example.

- Effectively-the user get what they want from the system e.g. if an ATM user requests $£ 100$ cash, the user should get this and not $£ 50$.

- Efficiently-this is the main point concerned with this research paper. If the ATM menus were improved it would make ATM use more efficient. For example users don't want to spend 5 minutes trying to find the correct way to insert their cash card and type their PIN and the amount of cash they want and then eventually leave without remembering to extract their cash card.
- Enjoyably-systems should be attractive and inviting. Generally if a system is effective and efficient to use, it should also be enjoyable to use as a consequence. However additional effort could be made in ATM interface design to make ATM's more enjoyable to use such as making the screens and menus become more colourful and have images. A lot of ATM's still just have a black background screen with illuminated text, which is quite dull.

The main objective of Kevin Curran and David King's study was to design a "best-of-breed" ATM menu system. This was achieved in the form of the OptiATM (means optimal ATM menu). However, it still provides an insight into the problems of ATM HCI issues.

As demonstrated by their experiments, the OptiAT$\mathrm{M}$ menu design is a more usable and efficient system than other available ATMs. The OptiATM system has designed an extra faction, which can resolve the problem of users having to reinsert their ATM cards to carry out another transaction and to speed up transaction time. The system could help improve user's basic everyday ATM transactions.

However the OptiATM system [4] is basic in the functions and services they offer. Many advanced AT$M$ machines offer an abundance of additional services including cash and cheque deposits, ability to pay bill$\mathrm{s}$ at terminal and top-up pay as you go mobile phone and purchasing tickets such as train or concert tickets. ATMs have become part of the modern world's infrastructure. They expect ATMs for convenience as much as they expect a good transport service. However, as the service offers grow, the ATM menu designs will become more complicated. This may lead to the systems becoming even more confusing for users and harder to choose. It is recommended that ATM designers consult extensively with ATM users to help them design and create easy-to-use and efficient ATM systems. The Figure 6 is the OptiATM User Options.

In the process of using ATM, many users will forget to take their card, which will cause some loss and bring a lot of inconvenience for the user. In some studies, the researchers also found the problem, thus designed a no card operation ATM system.

Portable ATM's or Independent Convenience Cash Dispensers work in a different manner in that (1) User inserts card;(2) Card is read and user is instructed to remove card and (3) User enters PIN and carries out transaction/s required[6]. This enables customer$\mathrm{s}$ to be offered 'another transaction' after withdrawing cash. Using this method of operation, customers 


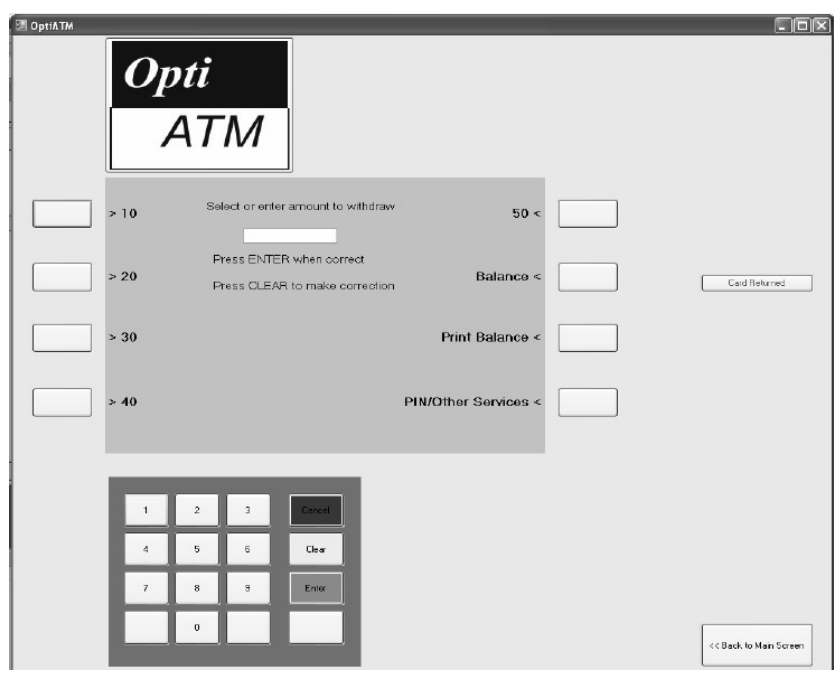

Figure 6 OptiATM user options

could withdraw cash and then be prompted 'Would you like another transaction?' This way, once the customer takes their cash, it is not possible to forget their card - as they already took it before they began their transaction. However, this creates a security problem on its own. What if the user just takes their cash and walks off without responding to the prompt 'Would you like another transaction?' Could the next user simply use the previous users account and withdraw cash? A fail-safe would be in place to ensure that this could not happen. If the user does not respond within a given time period e.g. 5 seconds for example, the session ends. In fact this fail-safe would be in place whenever a user is using the ATM at any given time.

The fact that the OptiATM design has the added facility of eliminating the need to reinsert ATM card$s$ and improving overall performance reinforces that the OptiATM menu design is an improved "best-ofbreed" ATM menu system [4].

ATM manufacturers have also demonstrated several different technologies which haven't yet gained worldwide acceptance.

- Biometrics for security purposes - the authorization of transactions is based on the scanning of fingerprints, the eye, face etc.

- Ability to print "items of value" such as traveler's cheques.

- Customers' specific advertising on the ATM.

\subsection{The secure design for ATM}

It has been found in the Jinping's survey research that [24], though the business category that ATM transacts is plentiful; most users only use the business of withdrawing money by ATM. The two functions of withdrawing money and checking balance have been frequently used. On the other hand, there are a large part of users who are not able to use ATM, especially the elders. Therefore, in the thesis the practical design of simplified ATM is only used for users to withdraw money, checking balance in automatic way, printing slips automatically, which simplifies operation procedures and probes into the futurist ATM new secure interaction, and futurist biometrics used in ATM.

The interaction between users and ATM is actually only two processes of identity authentication and withdrawal deposit. This design is through-the-wall ATM put indoors. It is divided into three levels according to users' operation sequences, the first level iris identification level, the second slot card level and the third withdrawal deposit level.

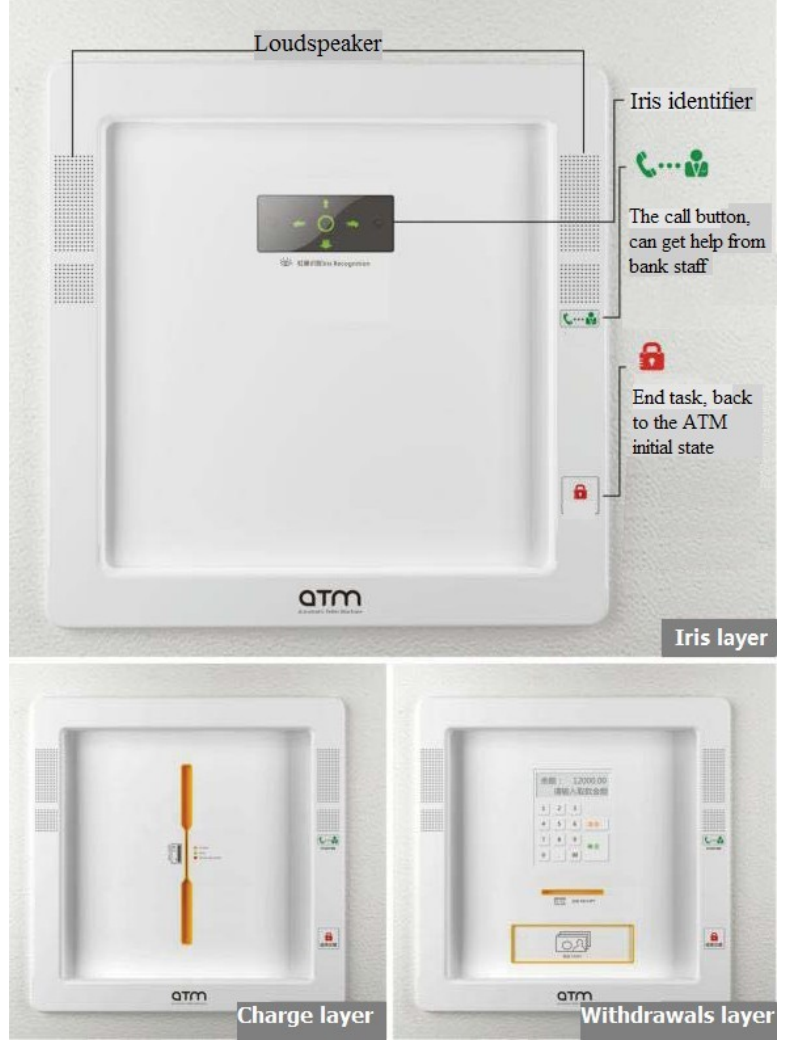

Figure 7 Sketch of simplified ATM three levels

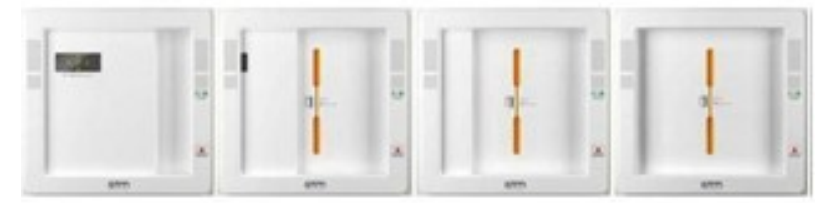

Figure 8 Sliding process from iris level to slot card level

Table 1 shows a classic description of interactive process between users and ATM [24]: when users with- 
draw money and get close to ATM, then look at iris identification equipment, the system identifies user$s$ ' iris and then slide way iris and slot card level appears; after users slot cards, the system will identify the matching of card and iris. If matching, it will be open and show withdrawal deposit level; users input an amount of withdrawal deposit directly and then confirm, the system will issue slip automatically, and then cashes come out. After users take away cashes, the system closes automatically and returns to the original status.

Table 1 The classic description of interactive process between users and ATM

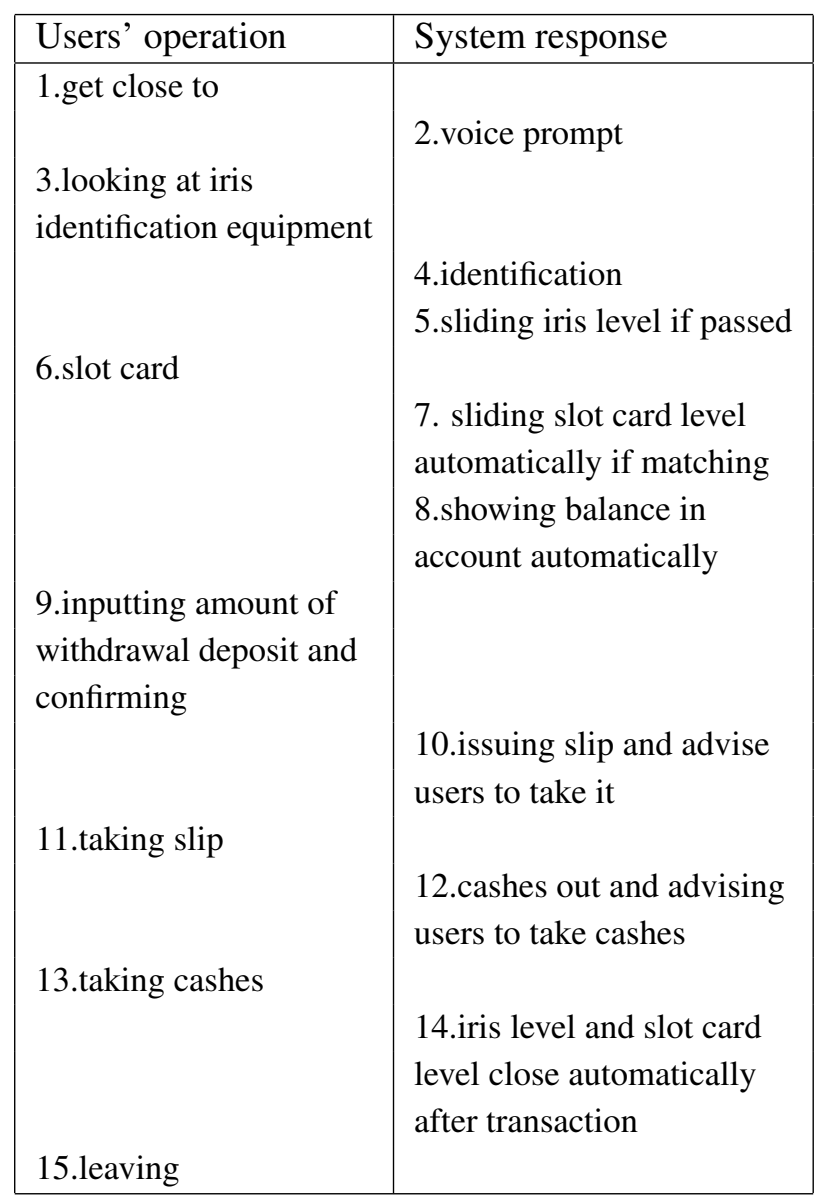

Simplified system adopts iris as the password [21]. Iris is a thin film existing inside eyeballs, possessing the characteristics of unchanging, unique, fast and exact to identify and strong in anticounterfeit. Iris identification is free of contact and memory, easy to identify, good to solve users' annoy of traditionally memorizing passwords, representing perfectly minimum users' memory.

In addition, the system also uses the Maintaining traditional setting of traditional slot cards[22]. On one hand, it is considered for mutual test. If users' iris is the only way of withdrawal deposit proof, it is easy to happen personal abuse aiming at users and threatening users with force; on the other hand, many user$\mathrm{s}$ have been accustomed to owning several banking cards and arrange different uses of each card in the survey; adopting slot cards, it is effective to avoid various concerns and risks of retaining cards; secondly, it can be identified by the system in the process of slotting cards.

In the process of design, principles of process guidance and binding are comprehensively used to simplify users' operation and guide users to operate stage by stage[20]; there are multichannel guidance in vision and audition for users' each stage of operation and corresponding feedback exist. After users withdraw money, the system will close automatically to end a withdrawal deposit flowing. Furthermore, use the faulty-tolerant principle: when there are any question or mistake in the process of users' using, closed trade key can be pressed to close transaction and return to the original status, which is like a reset function of computer. It allows users to make mistakes and operate in reverse, which can give users strong sense of security; using call button, bank officers will be directly connected to speak, which allows users to get in-time assistance. It effectively avoids swindling cases such as fake notice and fake service calls.

\subsection{The approach no card operation design for ATM}

Many advanced ATM machines offer an abundance of additional services including cash and cheque deposits, ability to pay bills at terminal, top-up pay as you go mobile phone and purchasing tickets such as train or concert tickets[5]. For these process of using ATM, many users will forget to take their card, which will cause some loss and bring a lot of inconvenience for the user. In some studies, the researchers also found the problem, thus designed a no card operation ATM system.

\subsubsection{Remove card before operation}

Portable ATM's or Independent Convenience Cash Dispensers work in a different manner:

- User inserts card.

- Card is read and user is instructed to remove card.

- User enters PIN and carries out transaction required. 
This method enables customers to be offered another transaction after withdrawing cash. Customers could withdraw cash and then will appear a promp$\mathrm{t}$ which said if users want to do another transaction. Once the customer takes their cash, it is not possible to forget their card-as they already took it before they began their transaction. However, this creates a security problem on its own. If the user just takes their cash and walks off without responding to the prompt, could the next user simply use the previous users account and withdraw cash? To solve this problem, a fail-safe would be in place to ensure the safety of the transaction. If the user does not respond within a given time period e.g. 5 seconds, the session ends. In fact this fail-safe would be in place whenever a user is using the ATM at any given time.

\subsubsection{No card operation}

In this way, the operation manner is that:

- Choose the transaction required.

- Input the card number.

- Put the money in ATM.

By this method, customers can already complete deposit and transfer business. Input the card number for twice, then put the cash in ATM, choose the deposit key that can easily finish the operation. However, it also has some disadvantages, for example, customers can't execute the withdrawing.

No card operation is a breakthrough of the ATM's design, which makes ATM more secure. People needn't worry about losing their card any longer.

\section{Conclusion}

The main purpose for this paper is to research the application of Human-computer Interaction Technology for financial terminal. Through the study of traditional ATM, we can find that ATM still has many defects which make users have some troubles in using ATM. For this reason, we have done a lot of surveys on present ATM's design on the precious literatures to sum up the shortcomings of ATM. These problem$s$ have been noticed by many scholars and we have made a survey of Marco and Kevin and other scholar's research. Marco think while engineers are required to develop reliable and highly performing systems, interaction designers and usability practitioners should solve usability problems and find solutions to improve the user experience. In the current study, the usability and the user experience of ATM of Banca was assessed by using both a heuristic evaluation and test with users. The main objective of Kevin and David's research was to design a "best-of-breed" ATM menu system. This was achieved in the form of the OptiATM. As demonstrated, the OptiATM menu design is a more usable and efficient system than the existed ATM's. The no card operation system was designed to resolve the problem of users having to reinsert their AT$M$ cards to carry out another transaction and to speed up transaction times.

ATM secure interaction involves in many aspect$s$ [24], such as technical design and artificial reasons of management and rules. With the intelligence technology and biometrics developing in ATM application, ATM secure interaction will be significantly improved. Meanwhile, ATM will be developing to the direction of more intelligent and more secure.

ATMs have become part of the modern world's infrastructure. We expect ATMs as a good transport service as much convenience as we expect. However, with the service offers growing, the ATM menu designs will become more complicated. This may lead the systems to become even more confusing for users and harder to choose. Therefore, ATM designers can consult extensively with ATM users to help them design and create ATM systems which are easier to use and efficient.

\section{Acknowledgments}

We would like to thank all the authors of the literatures which we surveyed. We appreciate the support from National Natural Science Foundation of China (61063027). We thank the members of Yunnan Compute Technology Application Key Lab in Kunming University of Science and Technology for their support and assistance. We are also grateful to anonymous reviewers for your insights.

\section{References}

[1] Brad A. Myers, "A Brief History of HumanComputer Interaction Technology", ACM, pp.44-54, 1998.

[2] Brumby, D.P., Cutrell, E., Sarin, "The path to evaluating a new interface for personal desktop search", Workshop paper presented at SIGCHI Conference on Human Factors in Computing Systems, R. Eyetracking in practice CHI'06, Montreal, Canada, 2006. 
[3] Fawzi Al Sawalqa, "Customers Financial Needs satisfaction and Self-service Technology Banking The Case of Automatic Teller Machines (ATMs) in Jordan", International Journal of Business and Social Science, Vol. 3 No. 9,pp.191-200,2012.

[4] Curran, K. and King, "Investigating the Human Computer Interaction Problems with Automated Teller Machine (ATM) Navigation Menus", Computer and Information Science, Vol. 1, no.2,pp.34-51, 2008.

[5] El-Haddad, A. B. and Almahmeed, M. A., "ATM banking behaviour in Kuwait: a consumer survey", International Journal of Bank Marketing, pp.25-32, 1992.

[6] Marco Camilli and Massimiliano Dibitonto, "User-centered design approach for interactive kiosks:evaluation and redesign of an automatic teller machine: ", Facing Complexity, pp.85-91,2010.

[7] Di Nocera, F., Coletta, S., Ferlazzo, F., Renzi, P. "Numerosit? del campione e stabilit? della stima di usabilit? ottenuta mediante valutazioni soggettive.", Giornale Italianodi Psicologia, pp.695-704, 2009.

[8] Nielsen, J., Perince, K. "Eyetracking Web Usability. Berkeley, CA", New Riders,2010.

[9] Charles Kalmanek, "A Retrospective View of ATM", ACM, 2002.

[10] J. P. KOHLI, "Designing an application oriented terminal”, National Computer Conference, 1975.

[11] Nielsen, J. Perince, K. "Eyetracking Web Usability. Berkeley, CA", New Riders, 2010.

[12] Pepermans, R., Verleye, G. Van Capellen S., “"Wallbanking", innovativeness and computer attitudes: 25-40 year-old ATM-users on the spot.", Journal of Economic Psychology, 17,pp.731-748, 1996.

[13] Mead, S., Walker, N. Cabrera, E.F. , "Training older adults to use automatic teller machines", Human Factors, 38,pp.425-433, 1996.

[14] Rogers, W. A., Cabrera, E. F., Walker, N., Gilbert, D. K. Fisk, A. D., "A survey of automatic teller machine usage across the adult lifespan.", Human Factors, 38,pp.156-166, 1996.

[15] Rogers, W.A. Fisk, A.D. , "ATM design and training issues", Ergonomics in Design, pp. 4-9, 1997.

[16] Rogers, W.A., Gilbert, D.K., Cabrera, E.F., “An analysis of automatic teller machine usage by older adults: A structured interview approach", Applied Ergonomics, 3(28), pp.173-180, 1997.

[17] Mankze, J.M., Egan, D.H., Felix, D. Krueger, H., "What makes an automated teller usable by blind users", Ergonomics, 41, pp.982-999,1998.

[18] Zhou Yi, Lv Aiguo, "Equipments and Application of Bank Cards", China Zhigong Publishing House, 1999.
[19] Biometrics, "New Protector of ATM", Computerized financial services, 2007.

[20] Li Leshan, "Human-Computer Interface Design", Beijing Science Publishing House, 2004.

[21] D. A. Norman, "The Psychology of Everyday Things", Beijing, China, China Citic Press, 2003.

[22] Huo Faren, "Research on Human-Computer Interface Design", Master's thesis of Wuhan University of Technology, 2003.

[23] Stefano Moano, "Ideas of Philips Design”, Beijing institute of technology press,2002.

[24] Chen Jinping, "A study of ATM secure interaction on user-based", IEEE International Conference, pp.306-310,17-19 Nov. 2010.

[25] Jun, M., and Cai, S., "The key determinants of internet banking service quality: a content analysis", International Journal of bank Marketing,19(7), pp.276-291, 2001.

[26] Giannakoudi, S., "Internet Banking: The Digital Voyage of Banking and Money Cyberspace", Information and communications Technology Law, 8(3), pp.205-243, 1999.

[27] Mcandrews, J., “Automated Teller Machine Network Pricing-A Review of the Literature", Review of Network Economics, 2(2), pp.146-158,2003.

[28] Maenpaa, K., Kale, S., Kuusela, H., and Mesiranta, $\mathrm{N}$, "Consumer perceptions of Internet banking in Finland: The moderating role of familiarity", http://epublications.bond.edu.au/business-pubs/89/, 2008.

[29] Rogers, W., Gilbert, D., and Cabrera, K., "An analysis of automatic teller machine usage by older adults. A structured interview approach", Applied Ergonomics, 28(3),pp. 173-180, 1997.

[30] Mirza, A., Beheshti, H., Wallstrom, A., and Mirza, O., “ Adoption of Internet Banking by Iranian Consumers: An Empirical Investigation", Journal of Applied Sciences, 9, pp.2567-2575, 2009.

[31] Gowrisankaran, G., and Krainer, J., "Entry and pricing in a differentiated products industry: Evidence from the ATM market", RAND Journal of Economic$s, 42(1)$, pp.1-22, 2011.

[32] Adepoju, A., and Alhassan, M., "Challenges of Automated Teller Machine (ATM) Usage and Fraud Occurrences in Nigeria - A Case Study of Selected Banks in Minna Metropolis", Journal of Internet Banking and Commerce, 15(2), pp.1-10, 2010.

[33] Rogers, W., Cabrera, E., Walker, N., Gilbert, K., and Fisk, A, "A survey of automatic teller machine usage across the adult lifespan”, Human Factors, 38(1), pp.156-166, 1996. 